American Journal of Pharmaceutical Education 2018; 82 (4) Article 6274.

\title{
RESEARCH
}

\section{Gender-Based Differences Among Pharmacy Students Involved in Academically Dishonest Behavior}

\author{
Eric J. Ip, PharmD, Jai Pal, MS, Shadi Doroudgar, PharmD, Monica K. Bidwal, PharmD, \\ Bijal Shah-Manek, PhD, B.Pharm \\ Touro University California College of Pharmacy, Vallejo, California
}

Submitted January 12, 2017; accepted March 18, 2017; published May 2018.

Objective. To determine whether differences based on gender exist among pharmacy students involved in cases of admitted cheating or other academic dishonesty and to assess perceptions of academic dishonesty.

Methods. Two cohorts of second-year male and female pharmacy students from four Northern California pharmacy programs were invited to complete a 45-item cross-sectional survey. Descriptive statistics and Pearson's chi-squared test were used for statistical analysis.

Results. There were 330 surveys completed with a 59\% response rate. No significant gender-based differences were found regarding admitted cheating in pharmacy school and in regards to participating in various forms of academically dishonest behavior. Female students were more likely than male students to report witnessing a classmate copying another student's assignment. Male students were less likely than female students to perceive a student who distributed a stolen exam as a cheater.

Conclusion. No gender-based differences were noted in cases of admitted cheating or with regards to taking part in various forms of academically dishonest behavior. However, female students report witnessing cheating more than male students, and male students may have a more lenient perception toward academically dishonest behavior than female students. The information gathered from this study may provide further insight to pharmacy programs and educators regarding academic dishonesty at their institution.

Keywords: pharmacy, cheating, academic dishonesty, gender

\section{INTRODUCTION}

Academic dishonesty has been reported in the literature from multiple health care disciplines. ${ }^{1-7}$ Academic dishonesty is any form of cheating or dishonest behavior in an academic setting. It is especially concerning among health care professional students as such behaviors could lead to continued unethical acts after graduation, which may adversely affect patient care. Examples of academic dishonesty may include, but are not limited to, examination cheating, receiving or disclosing content of an oral or practical examination, copying another student's coursework, fabricating laboratory data, or plagiarism. ${ }^{6,8,9}$ While academic dishonesty has been studied among various health care programs, limited data exists regarding potential gender differences, especially in professional pharmacy programs.

Corresponding Author: Eric J. Ip, Touro University California College of Pharmacy, 1310 Club Dr., Vallejo, CA 94592. Tel: 707-638-5993. Fax: 707-638-5959. E-mail: eric.ip@tu.edu
Few pharmacy studies have investigated gender differences concerning admitted cheating in pharmacy school, admission to performing various forms of academically dishonest behaviors, and perceptions of academic dishonesty. Regarding admitted cheating in doctoral-level pharmacy school programs, two studies did not show any significant differences between males and females. ${ }^{10,11}$ Two studies analyzed differences in academically dishonest behaviors amongst male and female students. ${ }^{10,12}$ Forinash and colleagues did not find any gender-based differences regarding examination cheating, group project cheating, laboratory assignment cheating, and plagiarism. ${ }^{10}$ However, Henning and colleagues reported that males took part in more collusion (eg, observing but not reporting a student copying another student's exam, taking an exam for someone else, removing reference materials from the library to prevent access for others, resubmitting work from one course to another course, and not reporting a classmate who was under the influence of alcohol or illicit drugs while on professional duty) than females. ${ }^{12}$ One 


\section{American Journal of Pharmaceutical Education 2018; 82 (4) Article 6274.}

study analyzed perceptions of academically dishonest behaviors among male and female students in a bachelor of pharmacy program located in Australia. ${ }^{13}$ Emmerton and colleagues, through the use of hypothetical scenarios, did not find any gender-based differences in perceptions of academically dishonest behaviors related to sharing details of an examination, copying another student's work, and plagiarism. ${ }^{13}$ Additional investigation is warranted regarding gender-based differences in academic dishonesty and perceptions of academically dishonest behavior among US Doctor of Pharmacy students.

The purpose of this study is to determine whether differences in male and female students exist regarding admitted cheating in Doctor of Pharmacy programs, taking part in various forms of academically dishonest behavior, and perceptions of academically dishonest behavior.

\section{METHODS}

A 45-item cross-sectional survey was distributed to students during a regularly scheduled class session at the four Northern California pharmacy schools (Touro University California College of Pharmacy, University of the Pacific Thomas J. Long School of Pharmacy \& Health Sciences, California Northstate University College of Pharmacy, and University of California San Francisco School of Pharmacy) between November 4, 2014 and March 21, 2015. Details of the methods have been described by Ip and colleagues wherein they assessed the prevalence, methods, and motivating factors of academic dishonesty in pharmacy students as well as if certain factors may put a student at a higher risk of performing such acts. ${ }^{6}$ The current study is a sub-analysis focusing on two cohorts, male and female second-year students who had not yet progressed to Advanced Pharmacy Practice Experiences (APPEs). Surveys with less than $80 \%$ of questions answered were deemed incomplete and were excluded from the study. Those who did not specify the survey taker's gender were also excluded. The survey assessed cheating history, performance of various forms of academically dishonest behavior, and perceptions of academically dishonest behavior. ${ }^{11,14}$ Perceptions of academically dishonest behavior were based on five hypothetical scenarios from Rabi and colleagues. ${ }^{11}$ The study received approval from Touro University California's Institutional Review Board.

Data analyses were conducted using STATA version 13.0 (StataCorp LP, College Station, TX). Means and standard deviations were reported for continuous data as a measure of central tendency, while frequencies and percentages were reported for categorical data. Pearson's chi-squared test was used to compare the differences of academic dishonesty between male and female students. Statistical significance was defined as a $p$ value of less than .05 .

\section{RESULTS}

Of the 560 students (192 male, 34\%; 368 female, $66 \%$ ) enrolled at four Northern California pharmacy school programs according to the American Association of the Colleges of Pharmacy (AACP), 360 completed the survey. ${ }^{14}$ Thirty surveys were excluded: 15 were incomplete, 14 were completely blank, and one did not indicate the gender of the survey taker. This resulted in a final sample of 330 students (115 male, $35 \% ; 215$ female, $65 \%$ ) for a response rate of $59 \%$.

Table 1 describes male and female students' cheating history and knowledge of cheating incidents at their pharmacy school. When asked if they have ever cheated in pharmacy school, there was no difference between males and females $(10 \%$ vs $13 \%, p=.57)$. Females

Table 1. Admitted Cheating History and Awareness of Male and Female Pharmacy Students

\begin{tabular}{|c|c|c|c|}
\hline \multirow[b]{2}{*}{ Scenarios } & Males & Females & \multirow[b]{2}{*}{$P$} \\
\hline & \multicolumn{2}{|c|}{ No. $(\%)$} & \\
\hline \multicolumn{4}{|c|}{$\begin{array}{l}\text { Have you ever cheated in } \\
\text { pharmacy school? }\end{array}$} \\
\hline Yes & $12(10)$ & 27 (13) & .57 \\
\hline No & $103(90)$ & $188(87)$ & \\
\hline \multicolumn{4}{|c|}{$\begin{array}{l}\text { Have you ever cheated in } \\
\text { undergraduate school? }\end{array}$} \\
\hline Yes & $20(17)$ & 40 (19) & .79 \\
\hline No & $95(83)$ & $175(81)$ & \\
\hline \multicolumn{4}{|c|}{$\begin{array}{l}\text { Have you ever cheated in high } \\
\text { school? }\end{array}$} \\
\hline Yes & $43(38)$ & $67(31)$ & .23 \\
\hline No & & & \\
\hline \multicolumn{4}{|c|}{$\begin{array}{l}\text { Have you ever cheated in middle } \\
\text { school/junior high school? }\end{array}$} \\
\hline Yes & $50(44)$ & 70 (33) & .049 \\
\hline No & $65(57)$ & $145(67)$ & \\
\hline \multicolumn{4}{|c|}{$\begin{array}{l}\text { Are you aware of any incident(s) } \\
\text { of cheating involving pharmacy } \\
\text { students at your institution? }\end{array}$} \\
\hline Yes & $56(49)$ & $129(60)$ & .058 \\
\hline No & $58(51)$ & $86(40)$ & \\
\hline
\end{tabular}




\section{American Journal of Pharmaceutical Education 2018; 82 (4) Article 6274.}

tended to be more aware of cheating incidents at their pharmacy school than males ( $60 \%$ vs $49 \%, p=.07$ ) however this difference was not statistically significant. While more males reported cheating in middle school than females ( $44 \%$ vs $33 \%, p=.05$ ), no gender-based differences were noted in reported cheating during high school or undergraduate studies.

Male and female students admitted to participating in various forms of academically dishonest behavior (Table 2). Engaging in various academically dishonest behaviors did not differ based on gender. However, over a quarter of both male and female students either gave (32\% male, $27 \%$ female) or received details (30\% male, $25 \%$ female) regarding contents of an oral/practical examination or Objective Structured Clinical Examination (OSCE), over a third (35\% male, 38\% female) reported copying another student's coursework with permission, and almost half ( $49 \%$ male, $47 \%$ female) reported giving coursework to students in other professional years.

Table 3 depicts five hypothetical scenarios. Students were asked to evaluate these scenarios and indicate if they perceived the actions as cheating, if they have witnessed the behavior in pharmacy school, and/or if they participated in the behavior in pharmacy school. Males were less likely than females to perceive a male student who was an examination theft accomplice and distributed the examination to his classmates as a cheater ( $45 \%$ vs $77 \%, p<.001)$. However, females were more likely to witness a student directly copying another student's calculations assignment ( $32 \%$ vs $19 \%, p=.02)$. No other sex-based differences were found regarding perception or participation in academically dishonest behaviors.

\section{DISCUSSION}

This study compared gender-based differences among pharmacy students regarding admitted cheating in pharmacy school, taking part in various forms of academically dishonest behavior, and perceptions of academically dishonest behavior. No significant differences were found between males and females in admitted cheating in pharmacy school as well as taking part in various forms of academically dishonest behavior. More females witnessed a classmate copying another student's assignment than males, and males seemed to have a more lenient perception regarding a student distributing a stolen exam.

Similar to the results of two US Doctor of Pharmacy program studies, this study found no differences in admitted cheating between male and female students. ${ }^{10,11}$
This study surveyed California pharmacy students, whereas the other two studies analyzed pharmacy students in Midwestern and Eastern states. From this, it can be inferred that differences in admitted cheating between male and female Doctor of Pharmacy students is unlikely. However, Aggarwal and colleagues found that more male students admitted to cheating than females in a Master of Sciences of Pharmacy program in England. ${ }^{15}$ Literature has shown that cheating tendencies decrease as students progress to professional-level programs. ${ }^{9}$ Data is mixed among medical students with two studies reporting higher rates of cheating among males, while another study reported no differences between genders. ${ }^{8,9,16}$ Males reported higher rates of admitted classroom cheating in nursing and physician assistant programs than females. ${ }^{17-19}$ Although no study has specifically associated academic dishonesty during didactic years to academic dishonesty in the experiential environment amongst cohorts of pharmacy students, one such study exists in medicine. Medical students who are academically dishonest are more likely to alter laboratory data, patient history, or physical examination findings in a clinical setting. ${ }^{8}$ Thus, it is plausible that the same may be true for pharmacy students who cheat in the didactic setting.

Gender-based differences in ethical behaviors of practicing pharmacists are implied in data available from the California Board of Pharmacy. Between 2015-2016, the California Board of Pharmacy reported that male pharmacists were more likely to have their licenses revoked or surrendered due to performing unethical professional acts (eg, medication theft, prescription falsification, and drug diversion) compared to female pharmacists. ${ }^{20}$ It should be noted that the majority of practicing pharmacists nationwide are female. ${ }^{21}$ Similarly, male physicians in California were more likely to be disciplined for unethical professional acts such as clinical negligence or incompetence, drug or alcohol use, sexual misconduct, and financial or tax fraud. ${ }^{22}$ Regarding males reporting more cheating in middle school than females, Ip and colleagues previously found that the only predictor for cheating in pharmacy school was cheating in undergraduate studies (OR 11.7; 95\% CI 4.4-31.0, $p<.001) .{ }^{6}$ Interestingly, cheating begets cheating. The investigators also found that the only predictor of cheating in undergraduate studies was cheating in high school (OR 25.1; 95\% CI 9.0-69.7, $p<.001)$ as well as the only predictor for cheating in high school was cheating in middle school (OR 29.4; $95 \%$ CI 15.7-55.2, $p<.001){ }^{6}$ There appears to be no differences in admitted cheating between males and 
American Journal of Pharmaceutical Education 2018; 82 (4) Article 6274.

Table 2. Admitted Academically Dishonest Behaviors of Male and Female Pharmacy Students

\begin{tabular}{llcl}
\hline & & Males & Females \\
Scenarios & No. (\%) & $P$ \\
\hline
\end{tabular}

Have you ever used hidden notes during a written or electronic examination in pharmacy school?

Yes

$2(2)$

$1(0)$

.25

No

$113(98)$

$213(100)$

Have you ever used an unauthorized electronic device during a written or electronic exam in pharmacy school?

Yes

$0(0)$

$2(1)$

.3

No

$115(100)$

$211(99)$

Have you ever copied from a neighbor during a written or electronic exam in pharmacy school?

Yes

$9(8)$

$15(7)$

No

$106(92)$

$198(93)$

Have you ever asked someone for the answer during a written or electronic exam in pharmacy school?

Yes

Have you ever asked a peer for details regarding content of an oral/practical exam or $\mathrm{OSCE}^{\mathrm{a}}$ in pharmacy school?

Yes

$34(30)$

$53(25)$

$81(70)$

$158(75)$

Have you ever offered details to a peer regarding content of an oral/practical exam or $\mathrm{OSCE}^{\mathrm{a}}$ in pharmacy school?

Yes

$58(27)$

78 (68)

$156(73)$

Have you ever copied another student's coursework with the student's permission in pharmacy school?

Yes

$40(35)$

$80(38)$

$75(65)$

$133(62)$

Have you ever copied another student's coursework without the student's permission in pharmacy school?

Yes

No

$1(0)$

Have you ever stolen an exam in pharmacy school?

Yes

$0(0)$

$211(100)$

No

$115(0)$

$0(0)$

$214(0)$

Have you ever handed down work to students in lower years for their use in pharmacy school?

Yes

$56(49)$

$59(51)$

$101(47)$

$114(53)$ 


\section{American Journal of Pharmaceutical Education 2018; 82 (4) Article 6274.}

Table 2. (Continued)

\begin{tabular}{|c|c|c|c|}
\hline \multirow[b]{2}{*}{ Scenarios } & Males & Females & \multirow[b]{2}{*}{$P$} \\
\hline & \multicolumn{2}{|c|}{ No. $(\%)$} & \\
\hline \multicolumn{4}{|c|}{$\begin{array}{l}\text { Have you ever copied directly from reference sources without } \\
\text { acknowledging the source or citing appropriately in } \\
\text { pharmacy school? }\end{array}$} \\
\hline Yes & $18(16)$ & $36(17)$ & .78 \\
\hline No & $96(84)$ & $176(83)$ & \\
\hline \multicolumn{4}{|c|}{$\begin{array}{l}\text { Have you ever fabricated laboratory data for a practical } \\
\text { laboratory in pharmacy school? }\end{array}$} \\
\hline Yes & $1(1)$ & $9(4)$ & .09 \\
\hline No & 114 (99) & 204 (96) & \\
\hline
\end{tabular}

${ }^{\mathrm{a} O b j e c t i v e ~ S t r u c t u r e d ~ C l i n i c a l ~ E x a m i n a t i o n ~}$

females during the didactic years of pharmacy school; however, further exploration is warranted for cheating and unethical behaviors that may occur during clinical clerkships and post-graduation.

Regarding taking part in various types of academically dishonest behavior, this study found no significant gender-based differences in cheating during a written or computerized examination, stealing an examination, asking for or giving away details of a practical/oral examination or OSCE, copying another student's coursework, giving coursework to students in lower years, plagiarizing, and fabricating laboratory data. However, both males and females frequently admitted to participating in behaviors such as sharing practical/oral examinations or OSCE details, copying another student's coursework, and giving coursework to students in other professional years. Perhaps these types of sharing activities may not be considered cheating to the students or perhaps they may feel compelled by peer pressure. ${ }^{9}$ Similarly, Forinash and colleagues did not find any gender-based differences regarding cheating on an examination or quiz, laboratory assignment, group project, and plagiarism. ${ }^{16}$ One study of medical students reported no gender-based differences for examination misconduct, unexcused absences, research misconduct, clinical misconduct, and other types of misconduct (eg, avoiding teamwork, forging signatures, and using another person's medical stamp). While there were no gender-based differences for many forms of academically dishonest behaviors, male pharmacy students may take part in more collusion or teambased cheating than females.

This study and the study by Emmerton and colleagues used hypothetical scenarios to assess perceptions of academically dishonest behaviors between male and female pharmacy students. ${ }^{13}$ In both studies, no perception differences between males and females were seen for sharing details of an examination, copying another student's examination, copying another student's coursework, and using another student's work as their own. While Emmerton did not assess perceptions of a stolen examination, the current study revealed that males were less likely to perceive a male student as an examination theft accomplice and distributing the examination to his peers as cheating compared to females. ${ }^{13}$ A possible reason for this difference may be that males view the above scenario as a form of team-based comradery. Alternatively, males have been shown to tolerate cheating behaviors more than females, and females have a more conservative view of cheating than males. ${ }^{23,24}$ Future studies may wish to assess whether perception differences exist regarding cheating or performing unethical behaviors on clinical clerkships and as a practicing pharmacist. It would also be interesting to assess if those who cheat felt any remorse in performing these academically dishonest acts in the didactic and clinical settings.

This study had a number of limitations. First, surveyed students were only from Northern California pharmacy schools. As such, the findings may not be generalizable to other states. Second, participants were completing the didactic portion of the PharmD curriculum and as such, cheating or unethical behavior in the clinical or patient care settings was not assessed. Third, there is a potential for recall bias as participants were asked to recollect past experiences. Next, students may have been subject to social desirability bias due to the subject matter. Lastly, rates of admitted cheating are likely lower than actual rates due to the sensitive nature of the topic and also the respondents' interpretation of the question "Have you ever cheated in pharmacy school?" (ie, some may only view cheating in relation 


\section{American Journal of Pharmaceutical Education 2018; 82 (4) Article 6274.}

Table 3. Hypothetical Scenarios to Assess Perceptions, Witnessing, and Participation of Academically Dishonest Behaviors of Male and Female Pharmacy Students

\begin{tabular}{lcc}
\hline & Males (n=115) & Females (n=215) \\
\cline { 2 - 3 } Scenarios & No. (\%) & $P$ \\
\hline
\end{tabular}

Mike and Laura have been dating for three years. Mike finished his Drug Information paper three weeks before it was due, and Laura, whose native language is not English, is struggling with writing hers. Laura writes an outline and part of the paper, but she is unable to finish it. She asks Mike to edit the paper. Mike rewrote the entire paper, and Laura turned it in.

Mike cheated.

$95(83)$

170(79)

$134(62)$

.44

Laura cheated.

$65(57)$

$13(11)$

14(7)

16(14) 29(14)

.31

This is not cheating.

.13

I have witnessed similar behavior during pharmacy

$0(0)$

$4(2)$

.14

I have participated in similar behavior during pharmacy school.

Karen and Tony are very close friends. Karen studied nightly for three weeks for her therapeutics examination, while Tony worked nightly until the day before the examination, leaving him little time to study the material. During the examination, Tony sat next to Karen and looked at her paper to make sure his answers matched hers. Karen was not aware of what Tony was doing.

Tony cheated.

Karen cheated.

$109(95)$

$6(5)$

$2(2)$

$11(10)$

$1(1)$ school.

I have participated in similar behavior during pharmacy
$204(95)$

6 (3)

$2(1)$

$36(17)$

$1(0)$
.97

.26

.26

.075 school.

If the scenario changed and Karen knew about Tony's cheating, did Karen commit cheating?
Yes, Karen cheated.
$96(84)$
$185(86)$
$27(13)$
.53
$18(16)$
.44

Bryan was feeling sick and missed a pharmaceutics examination scheduled for Tuesday. The professor said he could take a makeup on Friday. Later that Tuesday night, Bryan called up Lisa, Teresa and Rob, his friends from class, to find out what topics were covered on the examination. They all gave him as much information as they could remember.
Bryan cheated.
$86(75)$
$156(73)$
$155(72)$
.66
Lisa, Teresa, and Rob cheated.
$86(75)$
$13(6)$
$7(6)$
$58(27)$
.60
This is not cheating
$25(22)$
$14(7)$
.30 school.
I have participated in similar behavior during pharmacy
$3(3)$

Professor James assigns 30 calculations problems worth $10 \%$ of the final grade in the class that are due in five days. Jeff forgot about the assignment and remembers the night before they are due. He asks Ellen if they could work together so that they could finish the problems quicker. Ellen already finished 10 of the problems. Jeff copies the 10 directly and then works with Ellen on the other 20.

Jeff cheated.

$86(75)$

$52(45)$

$23(20)$

This is not cheating.

$22(20)$

$163(76)$

.84

I have witnessed similar behavior during pharmacy

$96(45)$

.92

$29(14)$

.12 school.

I have participated in similar behavior during pharmacy

$8(7)$

$20(9)$

.47 


\section{American Journal of Pharmaceutical Education 2018; 82 (4) Article 6274.}

Table 3. (Continued)

\begin{tabular}{lcc}
\hline \multirow{2}{*}{ Scenarios } & Males $(\mathrm{n}=115) \quad$ Females $(\mathrm{n}=215)$ \\
\cline { 2 - 2 } & No. $(\%)$ & $P$ \\
\hline
\end{tabular}

Robin and Homer knew that one of their professors always left his door unlocked. Three days before the examination, Homer waited outside the office door while Robin went into the office. Robin found the final examination and snatched a copy of it. Robin made a copy for himself, Homer and five of their other friends.

\begin{tabular}{|c|c|c|c|}
\hline Robin cheated. & $98(85)$ & $185(86)$ & .84 \\
\hline Homer cheated. & $52(45)$ & $166(77)$ & $<.001$ \\
\hline Their five other friends cheated. & $75(65)$ & $161(75)$ & .06 \\
\hline This is not cheating. & $5(4)$ & $2(1)$ & .05 \\
\hline This is the professor's fault & $15(13)$ & $20(9)$ & .29 \\
\hline $\begin{array}{l}\text { I have witnessed similar behavior during pharmacy } \\
\text { school. }\end{array}$ & $8(7)$ & $14(7)$ & .88 \\
\hline $\begin{array}{l}\text { I have participated in similar behavior during pharmacy } \\
\text { school. }\end{array}$ & $5(4)$ & $4(2)$ & .19 \\
\hline None of the above & $98(85)$ & $183(85)$ & .98 \\
\hline
\end{tabular}

to examination cheating). To address this limitation, multiple forms of academically dishonest behavior were assessed.

\section{CONCLUSION}

There were no significant differences between male and female pharmacy students regarding admitted cheating and the incidence of academically dishonest behavior. However, females report witnessing cheating more than males, and males may have a more lenient perceptions towards academically dishonest behavior than females. The information gathered from this study may provide further insight to pharmacy programs and educators regarding academic dishonesty.

\section{REFERENCES}

1. Al-Dwairi ZN, Al-Waheidi EM. Cheating behaviors of dental students. J Dent Educ. 2004;68(11):1192-1195.

2. Arhin AO, Jones KA. A multidiscipline exploration of college students' perceptions of academic dishonesty: are nursing students different from other college students? Nurse Educ Today. 2009;29 (7):710-714.

3. Dereczyk A, Bozimowski G, Thiel L, Higgins R. Physician assistant students' attitudes and behaviors toward cheating and academic integrity. J Physician Assist Educ. 2010;21(1):27-31. 4. Marques DN, Macedo AF. Perceptions of acceptable conducts by university students. J Optom. 2016;9(3):166-174.

5. Aaron L, Simmons P, Graham-Webb D. Academic dishonesty and unprofessional behavior. Radiol Technol.

2011;83(2):133-140.

6. Ip EJ, Nguyen K, Shah BM, Doroudgar S, Bidwal MK.

Motivations and predictors of cheating in pharmacy school. Am J

Pharm Educ. 2016;80(8):Article 133.

7. Dans PE. Self-reported cheating by students at one medical school. Acad Med. 1996;71(1 Suppl):S70-S72.
8. Sierles F, Hendrickx I, Circle S. Cheating in medical school. $J$ Med Educ.1980;55(2):124-125.

9. Baldwin DC, Jr., Daugherty SR, Rowley BD, Schwarz MD. Cheating in medical school: a survey of second-year students at 31 schools. Acad Med. 1996;71(3):267-273.

10. Forinash AB, Smith WT, Gaebelein CJ, Garavaglia J. Differences in self-reported academically dishonest and nondishonest pharmacy students when rating professional dishonesty scenarios. Curr Pharm Teach Learn. 2010;2 (2):100-107.

11. Rabi SM, Patton LR, Fjortoft N, Zgarrick DP. Characteristics, prevalence, attitudes, and perceptions of academic dishonesty among pharmacy students. Am J Pharm Educ. 2006;70(4): Article 73.

12. Henning MA, Ram S, Malpas P, Shulruf B, Kelly F, Hawken SJ. Academic dishonesty and ethical reasoning: pharmacy and medical school students in New Zealand. Med Teach. Jun 2013;35(6): e1211-e1217.

13. Emmerton L, Jiang H, McKauge L. Pharmacy students' interpretation of academic integrity. Am J Pharm Educ. 2014;78 (6):Article 119.

14. American Association of Colleges of Pharmacy.

Fall 2014 enrollments in doctor of pharmacy as the first professional degree (PharmD) 2014. https://www.aacp.org/sites/ default/files/2017-10/2014_PSS_Introduction.pdf. Accessed February 23, 2017.

15. Aggarwal R, Bates I, Davies JG, Khan I. A study of academic dishonesty among students at two pharmacy schools. Pharm J. 2002;269(7219):529-533.

16. Hejri S, Zendehdel K, Asghari F, Fotouhi A, Rashidian A. Academic disintegrity among medical students:

a randomised response technique study. Med Educ.

2013;47(2):144-153.

17. Krueger L. Academic dishonesty among nursing students. J Nurs Educ. 2014;53(2):77-87.

18. Kececi A, Bulduk S, Oruc D, Celik S.

Academic dishonesty among nursing students:

a descriptive study. Nurs Ethics.

2011;18(5):725-733. 


\section{American Journal of Pharmaceutical Education 2018; 82 (4) Article 6274.}

19. Vail ME, Coleman S, Johannsson MB, Wright KA. Attitudes toward academic dishonesty in physician assistant students. $J$ Physician Assist Educ. 2015;26(4):170-175.

20. California State Board of Pharmacy. Disciplinary actions. 2016; http://www.pharmacy.ca.gov/enforcement/discipline.shtml.

Accessed December 21, 2016.

21. Selmi M, Weil S. Can all women be pharmacists? A critique of Hanna Rosin's The End of Men. Boston University Law Rev. 2013;93:851-870.
22. Firth-Cozens J. Doctors with difficulties: why so few women? Postgrad Med J. 2008;84(992):318-320.

23. Saulsbury MD, Brown UJ, 3rd, Heyliger SO, Beale RL. Effect of dispositional traits on pharmacy students' attitude toward cheating. Am J Pharm Educ. 2011;75(4):Article 69.

24. Hardigan PC. First- and third-year pharmacy students' attitudes toward cheating behaviors. Am J Pharm Educ. 2004;68(5):Article 110. 